\title{
Spine-shaped elementary Sn: Its Preparation and Application as Anode Material for Lithium Ion Batteries (LIBs)
}

\author{
Hangchao Wang ${ }^{1}$, Xiaomi Shi ${ }^{2}$, Keqiang Ding ${ }^{1,2,3^{*}}$, Chenxue Li $^{2}$, Yanzhi Sun ${ }^{1}$, Hui Wang ${ }^{3}$, \\ Hongmin Dou ${ }^{3}$, Junqing Pan ${ }^{1 *}$ \\ ${ }^{1}$ State Key Laboratory of Chemical Resource Engineering, Beijing University of Chemical \\ Technology, Beijing, 100029, P.R.China \\ ${ }^{2}$ College of Chemistry and Materials Science, Hebei Normal University, Shijiazhuang 050024, P.R. \\ China \\ ${ }^{3}$ Hebei LingDian New Energy Technology Co., Ltd, Tangshan, Hebei, 064200, P.R.China \\ To whom the correspondence should be made: \\ *E-mail: dkeqiang@263.net, jqpan@mail.buct.edu.cn
}

doi: $10.20964 / 2018.08 .76$

Received: 14 February 2018 / Accepted: 4 April 2018 / Published: 5 July 2018

\begin{abstract}
A novel finding, that spine-shaped elementary $\mathrm{Sn}$ can be prepared by using a constant voltage electrolysis method, was reported for the first time in this communication. The well-defined spine morphology of the prepared sample was evidenced by the SEM image, and the formation of elementary Sn particles with relatively higher crystallinity was documented by the obtained XRD pattern. More importantly, the galvanostatic charge-discharge measurement results indicated that the initial discharge capacity of the prepared sample was as high as $439 \mathrm{mAh} \mathrm{g}^{-1}$ at $100 \mathrm{~mA} \mathrm{~g}^{-1}$, and after 20 cycles, the discharge capacity could be maintained at about $101 \mathrm{mAh} \mathrm{g}^{-1}$ under the current density of $100 \mathrm{~mA} \mathrm{~g}^{-1}$. Showing the preparation of spine-shaped elementary $\mathrm{Sn}$ was the main contribution of this work, which was not only beneficial to the development of anode material of LIBs but also very favorable to the improvement of microelectronic devices.
\end{abstract}

Keywords: Electrodeposition, Spine-shaped Sn, X-ray techniques, nanoparticles , Lithium ion battery

\section{$\underline{\text { FULL TEXT }}$}

(C) 2018 The Authors. Published by ESG (www.electrochemsci.org). This article is an open access article distributed under the terms and conditions of the Creative Commons Attribution license (http://creativecommons.org/licenses/by/4.0/). 